\title{
Socialization Through (Online) Design: Moving into Online Critical Spaces of Learning
}

\author{
Dennis Murphy Odo, Pusan National University \\ Christi Pace and Peggy Albers, Georgia State University
}

\begin{abstract}
This research investigates the social and socialization practices within an online professional development web seminar. The aim of this study was to identify the kinds of social and community building practices that occur in online professional development webinars by exploring how communication tools such as chat are used for community building and socializing purposes. Data was comprised of all electronically generated web seminar (webinar), written chat comment transcripts that were automatically generated during this series of webinars. Data were analyzed inductively and recursively using the constant comparative method. Findings revealed that the Online Web Seminars in Literacy project (oWSL) built community through moderators and participants greeting, assisting, and offering one another support. Moreover, social practices found within and across seminars included social talk, thoughtful debate, and the formation of nested affinity groups. This research revealed that this online professional development webinar provided a space where social practices like creating a sense of community through mutual support and engaging in productive disagreement among participants can stimulate informative critical dialogue that webinar organizers can draw upon to form dynamic and productive online professional development communities.
\end{abstract}

Keywords: Online communities of practice; socialization; web seminars (webinars); professional development; critical literacy

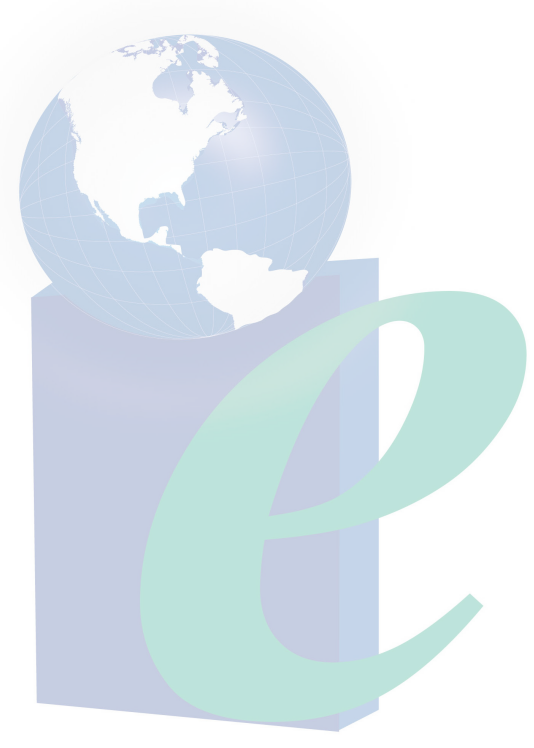




\section{Socialization Through (Online) Design: Moving Into Online Critical Spaces of Learning}

The rapid proliferation of digital technologies (i.e., Blackboard Collaborate, Twitter, MOOCS, Google docs, etc.) has changed the landscape of how teachers engage in language and literacy professional development. No longer confined by geographic boundaries of time and place, global others can now synchronously participate in professional teaching and learning opportunities, resulting in any time, any place learning. Brick and mortar boundaries once determined where and when people learned; today, advanced technologies have changed where, when, and how we learn. Kop, Fournier, and Mak (2011) contend that "the structure of the learning environment, the place and presence of learners and educators within the institutional boundaries, and the nature of knowing and learning are all challenged by the fast pace of technological change” (p. 74).

International Telecommunication Union (ITU) (2010) reports that there are over 5.3 billion mobile cellular subscriptions worldwide, and according to Ally and Samaka (2013), the digital hardware divide is disappearing. That is, more and more people access online resources through mobile and computer-mediated communication (CMC) devices; however, these researchers suggest that a learning divide has emerged between those who can afford learning materials and those who cannot. Such a divide has opened up the arena to countless open educational resources (OER) (Andrade et al., 2011), and yet, little has been written about OER that are not course-related (e.g., online classes, MOOCs). Further, access, once considered highly significant, has been questioned by a group of scholars who argue that how OER are used-or the pedagogy around open access resources - must be considered as highly significant in one's learning (Andrade et al., 2011; Ehlers, 2011; Gurell, Kuo, \& Walker, 2010). The work of these scholars, and others, extend the "focus beyond 'access' to 'innovative open educational practices' (OEP)” (Andrade et al., 2011, p. 2). According to these scholars, OER must be accompanied by a set of "educational practices" that "promote quality and innovation in teaching and learning” (Ehlers, 2011, p. 2). In essence, open access resources offer a wealth of information; however, without a sense of the practices to support learning, access to OER fundamentally may not be the key question. The most important question may be but how practice contributes to a deeper understanding of OER.

A relationship between OER and OEP has the potential, as Olcott (2012) argues, to transform the global education landscape. While literature in online spaces has identified the importance of access to OER and/or its challenges (Hylén, 2006; Keller \& Mossink, 2008) less is known about the social relationships and practices that emerge when open access resources like web seminars (webinars) have a pedagogical focus, especially in terms of professional development. While the literature regarding the nature of the social in online educational spaces (e.g., university online courses, MOOCs) has burgeoned in the last decade (Ashby, Sadera \& McNary, 2011; Santally, 2005; Sing \& Khine, 2006; Wanstreet \& Stein, 2011), insufficient research currently exists regarding the social within other educational online spaces such as web seminars, especially those that are on-going and focused on a singular area of research and practice. More specifically, especially with open access to online resources, research on social interactions, social practices, and on how such communities emerge and become established within web seminars is warranted. 


\section{Review of the Literature}

Much of what we know about socializing and socialization in online networked spaces developed out of a body of research on communities of practice (CoPs), a concept originally developed by Lave and Wenger (1991). As a sociocultural construct, learning within CoPs occurs through socially situated practice. Learning is a by-product of our lived experiences in and with the social world (Lave, 1991). Lave (1991) explains, "This view claims that learning, thinking, and knowing are relations among people engaged in activity in, with, and arising from the socially and culturally structured world" (p. 67). Learning, therefore, becomes at once culturally situated within social activity and transformative with practice or experience (Brown, Collins, \& Duguid, 1989; Lave, 1991). In online networked spaces, social activity typically takes the shape of participation in discourse exchanges, both spoken (e.g., using a microphone) and written, namely in the form of chat messages. Through our ongoing experiences, culturally and socially situated within activity (i.e., talk and cognition), we shape our identities in the worldwho we are, what we know, how we think. Language as social practice, thus, provides the medium for learning (Lave \& Wenger, 1991).

Full community engagement means understanding the beliefs, practices, language, and ways of being and acting in the social learning culture (Brown et al., 1989). Lave and Wenger (1991) explain, "As an aspect of social practice, learning involves the whole person; it implies not only a relationship to specific activities, but a relation to social communities-it implies becoming a full participant, a member, a kind of person” (p. 53). By engaging in socially situated practice, therefore, participants come to learn a community's norms and gain a sense of belonging, thereby making socializing and socialization integral components for fostering and sustaining learning, engagement, and identity within an online network of learners (Lave \& Wenger, 1991).

\section{The Socialization Process}

The process of socialization into a learning community, initially conceptualized in faceto-face communities, is a matter of prospective members becoming gradually acclimated and integrated into the community through the process of legitimate peripheral participation (Lave \& Wenger, 1991). That is, "The newcomer's participation at first is legitimately peripheral, but over time is centripetally drawn inwards and becomes more engaged and more complex" (Floding \& Sweir, 2012, p. 193). In this manner, the learner moves from marginal participation to central participation over time.

However, through Lave and Wenger's (1991) deconstruction of legitimate peripheral practice, we see three components that work in tandem to describe the social practice of learning: legitimate intimates various modes of belonging, while peripheral suggests degree of engagement, and participation denotes interaction. Hence, taken together, legitimate peripheral participation emphasizes learning through the social practice of engaging through participation. Participation so defined is not meant to imply an actual location designated as central or peripheral, but rather, "peripherality suggests that there are multiple, varied, more- or lessengaged and -inclusive ways of being located in the fields of participation defined by a community” (Lave \& Wenger, 1991, p. 36). In this sense, participation at all levels is recognized as important to the community's practice. So, while the socialization process takes place with the assistance of a few key current community members, Wenger (1996) comments that for a 
learning community to sustain itself, experienced community members (i.e., "old-timers”) must share their knowledge with new members or "newcomers" who also contribute to the community by developing new knowledge for the group. In this sense, Lave and Wenger (1991) posit, "The partial participation of newcomers is by no means 'disconnected' from the practice of interest" (p. 37). This socialization process takes time but it is vital to nourishing a community. Wenger (1996) states, "[in] particular, it takes sustained engagement in practice with old-timers in order for the depth and subtleties of practice to be shared with newcomers and for new generations to develop their own contributions” (p. 24). Thus, newcomers need continued engagement with oldtimers to become enculturated into the community and to reach full participation (Lave \& Wenger, 1991).

We see this as a behavioral process, and largely unidirectional, one in which current community members instruct the newcomer on the social behaviors of the community, which over time, do then fit into the norms of the community. The newcomer then becomes the oldtimer who instructs "newbies" in a similar fashion. We see this as a social process in which experienced community members instruct the newcomer on the social behaviors of the community, which over time, do then fit into the norms of the community. The newcomer then becomes the "old-timer" who instructs "newbies" in a similar fashion.

Figure 1: Behavioural and Social Process
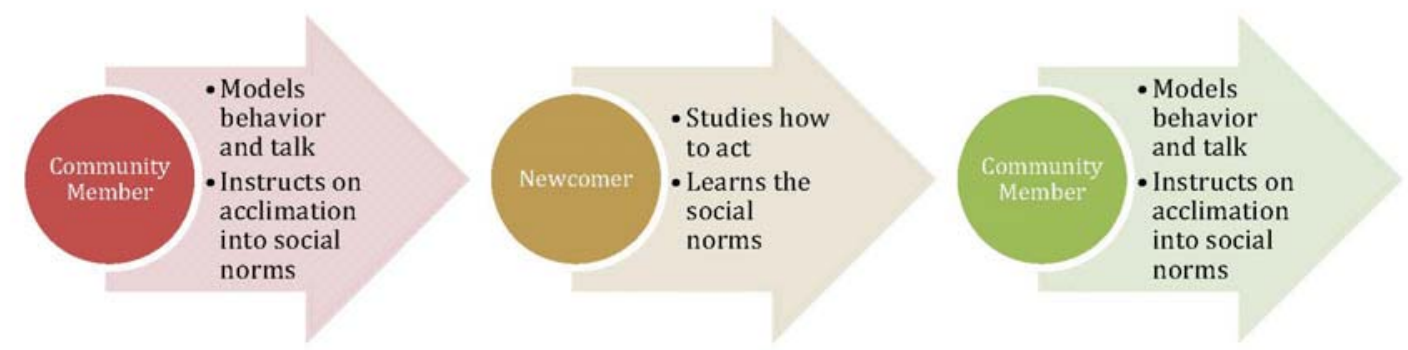

Particular veteran community members also contribute proportionately more to the socialization of new learning community members. In her study of online communities of K-12 teachers, for example, Booth (2012) found a number of voluntary informal roles being played by community members, which included that of mentor. She also concluded, "[these] unofficial roles...were based on both the personalities and the knowledgeability of the members who assumed them" (Booth, 2012, p. 21). Similarly, Brooks (2010) contends that "online CoPs that include both junior and senior faculty can serve many of the functions of traditional mentoring relationships without many of the associated complications” (p. 266), such as traditional barriers of race, class, gender, and disability. Also, Wenger (2009) describes the role of social artists (often moderators) who have an intuitive ability to facilitate social learning by making participants feel relaxed and involved. They are able to use their intuitive grasp of social dynamics to create and sustain productive social energy among participants that helps the community have a sense of making progress.

Online learning communities also provide options to participants in terms of unique interactional affordances (like anonymity) that some may prefer. Providing forums for online learning communities to develop along with face-to-face approaches to student or junior faculty socialization, development, and support may thus offer flexibility and accessibility, giving 
people options for developing relationships with their peers, especially those relationships that are so critical for acculturating into the academy. Online groups can be supportive spaces where participants can find a sense of belonging (Wellman \& Guilia, 1999). Some research is beginning to show that pre-service teacher participants expressed a strong intent to join online communities of praxis demonstrating that online social networks provide promising opportunities for students in teacher education programs to engage in beneficial professional development (Reich, Levinson, \& Johnston, 2011).

Social communications also contribute to the socialization of new community members. Researchers investigating social discourse in online learning communities report that social messages account for approximately 10\% (Schallert et al., 2009) to 27\% (Chen, Chen, \& Tsai, 2009) of all messages. Amin and Roberts (2008) agree that "virtual knowing seems to work best when technological and human intermediaries are available to help cultivate a 'net' sociality building on purposefulness, social interaction, and affective commitment” (p. 364). They add that an online learning community can reach a comparable level of social interaction and collaboration as face-to-face communities, but this online sociality has to take into account the physical distance between participants. All of these findings underscore the point that the social aspect of learning communities cannot be ignored. As Chiu, Hsu, and Wang (2006) observe, "People who come to a virtual community are not just seeking information or knowledge to solve problems but they also treat it as a place to meet other people, to seek support, friendship and a sense of belonging" (p. 1874). Therefore, the social aspect of online communities needs to be recognized as a key feature that attracts participants.

Stories are one means by which group members are socialized into learning communities and group identity is constructed (Wenger, McDermott, \& Snyder, 2002). Gray (2004) investigated online learning communities comprised of teachers and found stories to be a common means of fashioning group identity in the learning communities that she studied. Gray (2004) notes that through telling stories and shared problem-solving "the members of the group formed a social community ... through mutual engagement the group developed a shared repertoire of stories and cases that functioned as a dynamic knowledge source on which to base future practice” (p. 34). She concluded that stories shaped the identities of individual community members and the community as a whole as they used the online community to help them understand their work.

Community feedback is another means by which individual learning community members become socialized into the larger group. Within these learning communities, literacy teachers are able to articulate their tentative literacy understandings and thinking and receive supportive group feedback that generally reinforced or expanded on what they said (Bransford et al., 2000; Wenger, 1998). Additionally, participants' perceptions of community norms affect their sense of virtual community and willingness to publicly exchange support with other online participants (Blanchard, 2008). At other times, the feedback offers positive correction and the learning community can help refine the individual's understanding (Courtney \& King, 2009). Participation in these kinds of exchanges may also affect members' sense of self-efficacy (Takahashi, 2011). 


\section{Potential Inhibitors to Socialization}

In addition to the mechanisms and people that support socialization and continued regeneration of membership in online learning communities, several potential challenges also threaten the viability of these online learning communities. One is the development of close-knit cliques that become exclusive and overly focused on harmonious relationships (Wenger et al., 2002). Such a tight-knit group tends to suppress individual member contributions because they may fear being perceived as deviating from the community's thinking. Researchers contend that this groupthink and defensiveness can hinder the flow of honest and healthy internal critique that is necessary for learning communities to continue to grow in the understanding required to refine practice (Sing \& Khine, 2006; Wenger et al., 2002). Carr and Chambers (2006) point out that critical reflection on practice is vital for the free sharing of knowledge. This comment reveals how central a culture of open exchange of ideas is to the development of a vibrant learning community.

A second potential problem for some online learning communities can also stem from group cohesiveness. In his research with Emirati preservice teachers involved in an online community of practice, Clark (2009) concluded, "The price of the powerful coherence that has been fostered among community members...has been an 'otherization', as the community defines its beliefs, delineates its boundaries and unites its members in contradistinction to the 'constitutive outside' of the community" (p. 2343). That is, the community appears to achieve its sense of identity at the expense of members' negative views of non-members. Such an "us versus them" mentality may prove detrimental to the group as they interact with the wider community. Cloistering themselves in this way can cut the group off from potential sources of new knowledge.

Wenger, McDermott, and Snyder (2002) contend that excessive focus on egalitarianism is another potential short-circuit to communities flourishing. They argue that if participants do not have peer recognition in the form of status as an incentive there will be little motivation for them to innovate. Equally, Wenger et al. (2002) claim that an unproductive fixation on equality must be balanced against the risk of undue group stratification where some members feel more like "real members" that may prevent the formation of a common identity. Thus, it appears learning communities might walk the fine line of using status to encourage innovation while still allowing most participants to feel like genuine members.

A fourth danger is the overreliance on one "leader" (often the moderator), which can leave the community feeling lost if the leader departs. The presence of an overly powerful leader can also constrain open and honest dialog within the community (Wenger et al., 2002). Navigating the community leadership is no easy task. Moderators must struggle with how to facilitate meaningful discourse in an online space (Chen, Chen \& Tsai, 2009). Likewise, they are faced with the challenge of "how to provide a comfortable environment so that the participants are willing to share, and also push them to focus on the discussion topic and to reflect on their own knowledge and improve their practice” (Chen, Chen, \& Tsai, 2009, p. 1165). This observation indicates that the job of moderator is a somewhat delicate balancing act of ensuring participant comfort while meeting the social and knowledge sharing needs of the group.

Wenger et al. (2002) also note that some oversized and widely distributed learning communities may lack a clear identity and member commitment. In their research with widely 
dispersed in-service K-12 teachers in Australia, Carr and Chambers (2006) found an absence of perceived commonality of purpose among the participants, which in turn influenced their failure to buy in and prioritize accessing the online teacher learning community within the myriad of demands on their limited time. Wenger et al. (2002) also mentioned the threat of localism whereby widely spread out community members become isolated and unable to engage in idea sharing and community building. Additionally, an inability to attract new members is a serious threat to the long-term viability of any learning community. Thus, when communities fail to grow through procuring new members, developing new ideas and different ways of thinking and engaging in practice, they risk becoming stifled and collapsing (Li et al., 2009).

Inadequate participant knowledge can also be a significant obstacle to the sustainability of online learning communities. Even if they are motivated to join an online community, a shortage of technical knowledge about the topic of interest and experience in using computermediated communication tools will present a substantial barrier to potential members (Carr \& Chambers, 2006). Several additional obstacles relate to the generation of sufficiently deep knowledge building discourse during teacher professional development. These include participants' inability to detect gaps in their own understanding, inadequate knowledge of colleagues' teaching context, lack of social tact necessary to carefully express criticisms, and failure to view themselves as legitimate knowledge producers (Sing \& Khine, 2006).

Lastly, impediments to participants' willingness to work with others may also exist within the online space. For instance, in one study, undergraduate preservice teachers demonstrated reticence to collaborate in an asynchronous online course unless the cooperation was a feature of the course (Vonderwell, 2003). Wilson and Whitlock (1998) similarly noted that the majority of the undergraduate distance learning students in their study refused to collaborate online with others or do extra work due to their concerns about it being excessively time consuming.

As the foregoing discussion illustrates, researchers are beginning to identify the key sustainers and inhibitors to socialization within a variety of online learning communities. However, questions remain regarding the kinds of social and community building practices that occur in online professional development web seminars. This is particularly the case regarding how communication tools used in these spaces, such as chat, are used for community building and socializing purposes. Bearing this in mind, we asked the following questions to guide this component of a larger ongoing research project: (a) How are participants socialized into an online community interested in literacy, (b) how does "socialization" emerge in an on-going live literacy web seminar project, and (c) what social practices are visible within and across the web seminar project?

\section{Methods}

\section{Context and Researchers' Role}

The current investigation is part of an ongoing study of an online professional development web seminar project, online Web Seminars in Literacy (oWL), which features internationally renowned scholars in the field of literacy whose presentations are offered live online. As an open educational resource (OER) through the Blackboard Collaborate platform, anyone with an Internet connection can participate in the live web seminars by hyperlinking 
through the portal located on the oWL website. Those who are unable to attend a live seminar can access it on the oWL YouTube channel, which at this writing has had nearly 9000 views. While oWL serves as a venue where the audience may increase their professional knowledge of critical literacy issues, a number of questions remain regarding how the space is used in light of the social. The purpose, therefore, of the current study is to understand the role of the social in on-going, online professional development web seminar spaces, particularly oWL, in which participation is situated around critical issues in literacy.

This study occurred over the course of an academic year as we collected data for seven web seminars. Seminars were 1-hour long presentations delivered via Blackboard Collaborate software. Seminar presenters were world-renown scholars in language and literacy education. Participants were primarily teachers, administrators, graduate and undergraduate students in education and literacy scholars.

In terms of our own roles within the oWL project, one of the authors founded the project and the remaining authors served as moderators for the web seminars. Therefore, as researchers, we have a level of investment in the project that goes beyond that of a casual interest. Though we have striven to be conscious of the potential impact of our role in oWL on our research, we must acknowledge that this personal connection to the project may cause us to be unaware of subtle influence on our interpretations of our findings.

\section{Data Collection}

Data collection for the current study occurred from September 2012 to April 2013 across seven web seminars. Data were comprised of web seminar chat transcripts that were electronically generated during this series of web seminars. One chat transcript was generated for each seminar, and captured approximately 180 minutes of actual time, starting 90 minutes prior to the web seminar until approximately 15 minutes after the seminar ended. As the seminars were offered entirely online, all data were collected by saving and storing transcripts of participants' anonymous online chat comments made during seminars. Most screen names of participants did not reveal their identity and if we felt a participant's identity could be deduced from the transcripts, they were given pseudonyms.

\section{Data Analysis}

The research follows the procedures for what has been termed a "generic qualitative study” (Caelli, Ray, \& Mill, 2003; Lichtman, 2009; Merriam, 2002, 2009) that incorporates various elements from several qualitative research traditions. Data were analyzed using the constant comparative method (Corbin \& Strauss, 1990), which involved an iterative process of coding data sets and drafting analytical memos (Glaser \& Strauss, 1967) to generate and connect themes that addressed the research questions. Internal validity was addressed through our separate analysis of the data and documentation of initial themes. Coding began with our independent open coding of chat transcript data using RQDA software. Initial coding was followed by debriefing sessions where we compared our codes, negotiated meanings, and collapsed or eliminated less useful codes until we reached consensus on the central themes in the data (Lichtman, 2012; Merriam, 2009). We then organized our more carefully developed categories into an overall unified scheme of related categories and subcategories that addressed our research questions (Glesne, 1998) and generalized about the relationships among themes and concepts in the study (Bogdan \& Biklen, 2007; Gibbs, 2007; Hatch, 2002). 


\section{Findings}

Several findings emerged from this study, the two most salient are discussed here. The first finding indicated that socialization in oWLS occurs through community building. Our second finding suggests that social and socializing practices within and across seminars included social chat, disagreement and debate, and the formation of nested affinity groups. The specifics pertaining to these findings are outlined below.

\section{Socializing Through Community Building}

Socialization occurred through community building during seminars and was a prominent theme that emerged across the data. First, community building emerged through social practices initiated by moderators' encouraging interactions. Second, it was made visible through oWL participants' (both first and multiple timers) as they offered greetings, assistance, and mutual encouragement to other participants.

Moderator encouraging interactions. Valuing and validating others' comments, connecting to comments, and extending comments all contribute to socializing in this space. oWL moderators contributed to community building by both explicitly and implicitly encouraging interaction with speaker and participant views throughout the seminars. Moderators explicitly did this first, during the introduction of each seminar by verbally explaining how participants could interact using the chat box, while at the same time referring to a PowerPoint slide with instructions for how to do this, and second, during seminars, when they prompted participants to ask questions. The excerpts below show instances of the moderators explicitly encouraging participants to interact with the presenter's ideas by asking questions across three different seminars.

Fall 2012 Seminar 3

1:45:03 - [Moderator 1]: [Participant], do you have a question?

Spring 2013 Seminar 4

34:19 - [Moderator 2]: Please write your questions into the chat area when they arise for you.

Spring 2013 Seminar 1

1:21:52 - [Moderator 3]: Hello, everyone. Please feel free to type your questions into the chat window and I can ask them to Dr. [Presenter].

By asking questions such as “Do you have a question?” or "Please write your questions...”, moderators explicitly socialize participants that writing in the chat is part of the seminar experience, and even more descriptive is the type of writing questions. oWL moderators also prompted participants to ask questions in preparation for the Q\&A that follows the presentation. Further, moderators' suggestions position participants, especially those who may be new to online seminars, to know what to expect and how to participate in this setting. 
In addition to the explicit question prompts, moderators indirectly and implicitly encouraged interaction within the chat, demonstrating types of comments that participants might themselves write. Further, moderators' comments demonstrate their own involvement in the seminar, and connection to issues that the presenter raised. This form of moderator participation took place through chat comments they made during presentations. The three excerpts below show moderators sharing their own thoughts across three different seminars.

Fall 2012, Seminar 3

2:27:28 - [Moderator 2]: Yes...art often provides an avenue for ELs to express their ideas

\section{Fall 2012 Seminar 1}

2:22:40 - [Moderator 1]: Yes, and kids talk to each other about the cards and games. It becomes part of their discourse.

\section{Spring 2013, Seminar 1}

1:26:01 - [Moderator 2]: That's really interesting...how these woman present themselves...never thought of how I look in pictures and how I might be viewed over and across pictures

Each of these moderator chat comments was made on the content of a presenter's remarks. The moderators expressed agreement with the presenter's comment and added a thought of their own. This type of self-disclosure demonstrated for other participants how they, too, could use the same type of discourse to engage around the ideas in the presentation through participation in the chat. Moderator remarks also served to draw other participants into conversation around the topics being presented, offering an opening for participants who might feel intimidated or reluctant to immediately get involved. Moderators' comments to other participants' statements also appear to have tacitly encouraged seminar participants to see oWL as an interactive space to talk back to the ideas being presented. These moderator remarks could serve to engage the participants in further conversation and demonstrate to other "lurkers" that the chat space can be used in this way.

Spring 2013, Seminar 7

30:37 - [Moderator 3]: Exxon has been doing STEM commercials throughout the Masters

\section{Spring 2013, Seminar 4}

1:36:52 - [Moderator 2]: Interesting question, [Participant]—are they intending this information for themselves even though others can see this?

One moderator was even more explicit in her community building throughout the seminars as she reached out to participants to inform them that their presence was valued within 
the space. For example, during Seminar 2, she typed, "We hope all of you will join us for all of our speakers-they're really top notch!” In Seminar 5, this same moderator typed into the chat box, "Yes...staff, faculty, students, and the public...we would love to see the public come in!" These comments reveal the moderator's commitment to encourage participants to continue to return to the space across time and to develop a sense of inclusiveness of participants. Such encouragement of other participants to contribute to the discussion, according to Butler, Sproull, Kiesler, and Kraut (2007), serves to "ensure that the group does not collapse due to abuse of the public space created by the communications infrastructure, and to render the group a comfortable and enjoyable place to interact” (p. 5-6). These researchers also note that social management is particularly crucial for online communities because participants are able to leave more easily than in face-to-face groups whose members may have more binding ties to the community or space. Therefore, moderators' efforts to generate participant interaction within the oWL web seminar space serve as important attempts at community building and community maintenance.

Participants greeting, helping, and mutual encouragement. Another example of community building in oWL web seminars was the greetings shared among participants. These greetings took the form of various salutations among individual participants, subgroups (e.g., classes), moderators, and speakers. The exchange of greetings included moderators greeting all new entrants into the web seminar space. Other individual participants also greeted people they knew or had met in previous oWLS web seminars. This frequent exchange of salutations by such a wide variety of participants appeared to create a welcoming and collegial atmosphere.

Community building also occurred through participants' occasional attempts to forge connections among themselves during seminars. As demonstrated below, participants primarily connected over their shared interest in the presenter's scholarship. Some solicited the group to see if anyone shared an interest in a particular topic. Still, others attempted to reach out to someone from his or her local area through the chat. Moderators did not prompt these participants' attempts to make connections and build community among themselves. These spontaneous attempts at community building suggest that participants view the web seminar as a community space where they can connect with peers who share their interest in critical literacy issues.

Spring 2013, Seminar 6

[Participant 1] to [Participant 2]: I'm doing a study using Dr. [Presenter] ideas, it would be nice to talk to other people who are interested in her concepts too

[Participant 2] to [Participant 3]: found you on FB and small world we have a friend in common :) I hope we can keep in touch.

Fall 2012, Seminar 1

2:48:44 - [Participant 1]: I would love to join in blogging over international and/or multicultural literature....anyone out there interested?

2:49:15 - [Participant 2]: I would love it, [Participant 1]!! 
We must note, however, that not all invitations to make connections were accepted. For instance, during the seventh and final web seminar of the 2012-2013 season, one participant poses a question to the whole group of participants asking, "Hi, is there anyone in here from STL?" but receives no reply. In another example, a participant asks another participant, "[are] you in atl [?]" but again does not get a response. We acknowledge, therefore, that not all web seminar participants may feel an equally strong sense of community or willingness to engage with fellow participants. Of course, there may also have been other reasons why other participants failed to respond such as no one being from that location or those from that location failing to see that particular chat message due to not following the chat at that time.

Another way that community building emerged was when oWL participants assumed the role of informal helper through offering guidance on navigating the space. This guidance included advice on how to launch videos, adjust the sound, view the presenter's slides, as well as access the archived seminars. The following excerpts illustrate participants' willingness to provide assistance.

Spring 2013, Seminar 6

[Participant] to: ... Moderators I've just noted that only a few particiapnts [sic] have access to the whiteboard tools - the last column in the Participants list as I see it.

Fall 2012, Seminar 2

1:11:07 to: [Participant] you don't have to do anything with the sldies [sic] the presenter changes these so we are currently on slide 8 which has the model displayed.

\section{Spring 2013, Seminar 7}

1:20:47 to: [Participant 1] really wish if I could have access to the whole thing again

1:21:02 to: [Participant 2] it will be archived

In the first excerpt above, a participant has sent a chat message to all of the moderators regarding her observance that some participants cannot access the Blackboard Collaborate tools, thus showing her concern for her other participants. In the second example, a participant is observed instructing another participant, most likely one new to oWLS presentations, about who controls advancing the slides. Finally, in the third interaction, P2 explains to P1 how she can "have access to the whole thing again" through the archive. Participant willingness, thus, to share this information during seminars reveals some level of commitment to the space and to the other participants, as well as a sort of mentoring less experienced participants. We also interpret this to mean that oWLS participants have enculturated the norms for using the technological tools of the online space, navigating the space, and the social norms for offering navigational assistance.

Finally, community was fostered within oWL through supportive feedback comments made in chat interactions as well. An illustrative example of this was participants' sharing encouragement for others' contributions to the chat. These encouraging remarks included comments to express agreement with each other such as "I agree," “exactly," and "so true." 
Participants also occasionally gave general praise for each other's statements like "interesting point," "good point," or "good question." Additional broad positive exclamations included "bravo," "that's great" or "nice call.” At times, participants took advantage of semiotic devices such as creating smiley faces and using exclamations to show emotion. Along with these brief encouraging remarks, participants also shared more extended responses that often involved personal connections to the original comment, as the following two conversations demonstrate.

Spring 2013, Seminar 5

2:42:30 - [Participant 1]: Telling stories orally is another way non-"reading" parents can participate and encourage literacy

2:42:52 - [Participant 2]: i [sic] like that idea [Participant 1]

2:43:02 - [Participant 3]: Yes, regardless of the language oral stories happen in.

2:43:08 - [Participant 4]: Yes, good point [Participant 1]. I make up stories with my nephew all the time. There isn't a book or any pictures. We just use our imagination and my nephew is VERY creative in telling stories. :)

In this first conversation (Spring 2013), P1 offers a possible solution for parents who do not speak English to support their children's literacy development, while P2, 3, and 4 provide responses in the form of positive feedback that indicates support and acceptance of P1's idea about telling stories. The second discussion (Fall 2012) ensues when P1 explains how she integrated technology through a blogging activity involving her students and graduate students. P2 then offers how she has used blogging in the past, affirming the strategy as "free and interactive."

This growing sense of community was also explicitly mentioned and praised during web seminar chats. For instance, during seminar 6, one participant stated, "This community is incredible!!!” and another said, "This is a wonderful initiative and community.” That participants applied the discourse of "community" to describe oWL suggests that these participants clearly identify oWL as a communal space. A participant during seminar 5 also remarked that it was "nice to be a part of the conversation," indicating a feeling of involvement that points toward a sense of community belonging.

The preceding discussion provides evidence that community building occurred in oWL web seminars through moderators' encouragement of interaction in the space and participants' community-oriented behaviors of greeting, helping, and offering mutual encouragement. The following section will explore our second finding concerning the kinds of social and socializing practices within and across seminars, as evidenced by the chat transcripts.

\section{Social and Socializing Practices}

This study's second finding is that social and socializing practices were made visible within and across seminars. These practices involved social chat, disagreement and debate, and the formation of nested affinity groups.

Social chat. A variety of social interactions took place among participants within the oWL space. Moderators tended to interact with presenters primarily during practice sessions, just prior to the start of seminars, and after each seminar, once participants had logged out or had 
been removed by the moderator of the Blackboard Collaborate room. During practice sessions and just before the start of a seminar, moderators and presenters often engaged in social talk about topics such as local weather, mutual hobbies (e.g., art), and upcoming events in the literacy education world (e.g., conferences). After seminars, moderators engaged presenters in a brief interview about their experience presenting in a live seminar. Minimal social interaction was observed among the moderators during the actual seminars, with most of their social chat occurring before and after the seminars. We attribute this lack of moderator social interaction during seminars to the fact that their role as moderators kept them busy with attending to technical tasks, helping participants with navigational issues, and engaging participants in chat.

Participants (including moderators), on the other hand, engaged in a wider range of social interactions during the web seminars. Many of these interactions involved "chit-chat" and on the surface appeared to serve no purpose beyond exchanging pleasantries. Yet, upon analysis within and across chat transcripts, patterns emerged of participants reconnecting with colleagues physically located miles apart, reminiscing with friends, and even occasional joke telling. The few excerpts below are examples of the many instances when such socializing occurred across several different seminars.

Fall 2012, Seminar 1

[Participant 1]: Hi [Participant 2]!! How's everything in Winnipeg?

[Participant 1]: [Participant 2], are you still working with [scholar's] drama approaches?

Spring 2013, Seminar 4

[Moderator 1]: I'm used to snow I come from South Dakota...where the drifts were about 6-8 feet at times!

[Moderator 2 to [Moderators 1, and Speaker]: None in Atlanta either, in case you were wondering

[Moderator 2]: No snow in Atlanta

[Participant 2]: we are -37 Celsius with the wind chill in Winnipeg

Social interactions, such as the ones above, indicate that the oWLS web seminars provide a space where participants, should they choose to do so, engage in social exchanges, and that such social interactions suggest a kind of socializing that would be expected within the boundaries of a communal space in which participants feel, perhaps, a sense of belonging and comfortable conversing.

Disagreement and debate. Although participants were generally respectful and collegial, chat interactions were not always free from disagreement or debate. In fact, at times, communications could be somewhat provocative as participants challenged one another's chat comments. The excerpts below illustrate some of the more confrontational interactions that took place during web seminars.

Fall 2012, Session 3 
2:16:23 - [Participant 1]: A lot of English language learners engage in quite complex registers outside of school. One of my students (first language Spanish) teaches high school and one of her students is highly engaged, knowledgeable, and conversant in the cognitively complex language of horses (i.e., dressage). Her teachers, though, argue that she as "trouble" with academic language.

2:17:31 - [Participant 2]: just because she's mastered the "academic language" of horses doesn't mean she's mastered it in general, though. like writing a formal paper or something

2:19:36 - [Participant 1]: I understand-I haven't mastered the academic language of everything, either. I'm bothered that what she DOES know is not valued and it's false to say she does not have a.l.

\section{Fall 2012, Seminar 1}

2:32:43 - [Participant 1]: Let's not pretend that any 'game' is ideologically neutral.

2:32:57 - [Participant 2]: What are they, [Participant 3]?

2:33:03 - [Participant 4]: [Participant 1], how so?

2:33:06 - [Participant 5]: @[Participant 6] as a mom, I don't see my son going on to HS for the 4 years. There $r$ so many other ways to learn that are enjoyable.

2:33:09 - [Participant 7]: What in the world is ideologically neutral?

2:33:14 - [Participant 7]: Is anything in the world ideologically neutral?

\section{2:33:15 - [Participant 2]: Nada}

The first exchange illustrates a brief disagreement between two participants, P1 and P2, in which P2 attempts to give an example of student knowledge of horses as qualifying as a type of academic language that is undervalued in schools. However, P1 disagrees that knowledge of technical language of horses ensures the student has mastered many of the academic genres of school. P2 responds that his/her point is that the student's knowledge of technical language is not valued at school. In the second exchange, P1 mentions that games are not ideologically neutral to which P2 asks if anything is and P7 responds, "nada," apparently referring to nothing being ideologically neutral. This interaction demonstrates one participant pressing another on what he perceived as a simplistic statement. Meanwhile, P4 and P5 simultaneously engage in independent chat, unrelated to each other and the other participants. Thus, several distinct conversations may occur simultaneously but due to chat's linearity, these conversations appear as a single dialogue, rather than as several distinct conversations. Nevertheless, these two exchanges highlight the fact that while oWL generally appeared to be a respectful space, participants were willing to challenge other participants' ideology around important critical literacy issues, even at the risk of offending one another. Wenger (2000) identifies these kinds of challenges as “tensions" and sees them as important for new learning to occur, stating that "learning so defined is an interplay between social competence and personal experience. It is a dynamic two-way relationship between people and the social learning system in which they participate” (p. 227). Wenger 
defines social competence as knowing the norms and behaviors that it takes to be seen as a community member. Hence, social learning in a community is a convergence of the community's social competences and the lived experiences that we bring to the community. In this way, transformative learning occurs as the community continues to grow (Wenger, 2000).

Nested affinity group formation. An intriguing social practice within oWL is the formation of what we have identified as small parallel "affinity groups" in the chat sessions that took place throughout the web seminar (Albers, Pace, \& Brown, 2013). The interaction below illustrates three simultaneous discussions taking place among several affinity groups.

Conversation 1:

Fall 2012, Seminar 1

1:01:38 to: [Participant 1] Yes, the new test [sic] in my school district are now mostly extended response.

1:01:41 to: [Participant 2] Going back to the hornworm example - the language in the second example was more complex than the language in the first example. Would you say that the two statements are about different worlds?

\section{Conversation 2:}

1:02:06 to: [Participant 3] I like how engaging children with language can go across all of the content standards not just reading

1:02:10 to: [Participant 4] wouldn't experiences reading the world vary for individuals? How can teachers with goals of language literacy for students create experiences reading the world?

\section{Conversation 3:}

1:02:18 to: [Participant 5] [Participant 1], I LOVE THAT!!!!!!!! What state are you in? I think the NY state is still divided between MC and [extended response].

1:02:19 to: [Participant 6] The transition to the Common core empahsizes [sic] both the oral dialogue and the "reading the world" mentality by having students use technology and resources to help them understand academic vocabulary

The above excerpts identify three separate conversations happening concurrently within the same time frame and that connect to points that the presenter made during the web seminar. The first exchange between P1and P2 is about the types of test questions used in a respondent's district, while in the second conversation, P3 and P4discuss the idea of "reading the world." The third dialogue between P5 and P6 focuses on language across numerous content standards. Participants appeared to weave in and out of a number of these groupings throughout the course of any seminar. Their length of time spent in any single group discussion seems to depend on their interest in the topic and whether or not they are drawn toward other discussions vying for their attention. We have termed these clusters of participants "nested affinity groups" because they are flexible as they form and re-form around various topics throughout the course of the web seminar. Again, the linearity of chat makes these conversations appear to occur unilaterally when in real time, they are taking place simultaneously. We find this to be a unique feature in 
that all participants are privy to the information exchanged in all three conversations and can choose which ones, if any, they want to take up. These affinity groups further allow participants to move in and out of a variety of different conversations happening in the chat space that relate to points raised in the seminar that interest them. Affinity group participants are only bound to each other as long as the conversation continues though they can leave at any time. In this way, these affinity groups can be conceptualized somewhat like affinity spaces except they are organized around topic rather than permanent membership or space. Although Gee (2010) has explored the concept of affinity spaces in some depth, there does not seem to be as much literature around how participants in synchronous online spaces configure and reconfigure around the various points of interest raised in a web seminar.

Our data revealed social chat, disagreement and debate, and formation of affinity groups around various topics as instances of social and socializing practices that occurred during the oWL web seminars. Each of these oWL social practices connects to the key features identified as prerequisites for a vibrant online social space. The social chat observed demonstrates an atmosphere of trust among participants and the willingness to engage in debate shows focused and open interchange of ideas, while the affinity groups show a space that inspires selfexpression to which all participants have access. All of these features of the space indicate that oWL is a virtual place where a variety of social interactions occurs. Additionally, limited discussion currently exists in the research literature regarding the role that disagreement and debate can play in these online spaces. Through the present research, we have learned that web seminars can provide a democratic space where participants with divergent perspectives can share their views and engage in productive disagreement around the issues being presented.

The knowledge sharing that occurred through "nested affinity groups," the social and socializing practices visible within and across seminars, and the oWL community practices all help define oWL as a unique kind of learning community. We began this discussion with a statement that oWL did not appear to fit neatly into current conceptions of learning communities. Our findings related to knowledge sharing and social and community practices supported this claim. Therefore, we drew upon the work of several scholars to include the concepts of networks, affinity spaces, and praxis that we propose comprise the kind of distinctive learning space we believe oWL represents.

\section{Discussion}

The main purpose of this study was to explore the social and community building practices visible in a teacher professional development web seminar series that is dedicated to discussing critical literacy issues. A key finding was that community building occurred through moderatorencouraged interactions, participant greetings, helping, and mutual encouragement. Social practices that occurred within and across seminars included social chat, disagreement and debate, and the formation of nested affinity groups.

These findings are noteworthy for a number of reasons. First, the observation that community-building actions of many seminar participants contributed to a generally collegial atmosphere of good will highlights the importance of the plurality of routine actions and interactions to the collegial atmosphere of an online community. It also reminds us that in many ways moderators and core members serve as role models for new participants. Additionally, the social chat, productive disagreements, and nested affinity groups exemplify the various social 
practices that occurred across the oWLS series of web seminars. These social practices reveal these seminars as a space where participants engaged in forms of social interaction that, as yet, have not been unidentified in previous research.

In terms of community building, the foregoing discussion demonstrates how oWL moderators often function as social artists (Wenger, 2009) who facilitate social learning by nurturing online sociality (Amin \& Roberts, 2008) and supporting the social relationships and the sense of belonging that participants desire (Chiu et al., 2006) through their ongoing encouragement of interaction in the space. In contrast, the findings for participant greetings, helping, and mutual encouragement appear to contradict previous research, which found that when students do not see each other, they can ignore each other's help requests (Vonderwell, 2003 that they may perceive as being too time consuming (Wilson \& Whitlock, 1998). We must note, however, that the only extant related research was conducted with asynchronous online classes so we must use caution when relating these scholars' results to the present study. Participants' willingness to offer assistance to each other may depend on the type of online space (e.g., formal class versus web seminar) and possibly whether or not the space is synchronous. It may be that competition for grades in classroom communities or other reasons for gathering in the space (e.g., course credit versus professional development) affect participants' willingness to assist one another. Only additional research can answer this question.

Wellman and Guilia (1999) contend that when messages of support are exchanged publicly, participants perceive the group as being very supportive and all group participants benefit from the supportive exchanges even though they may not have directly participated in them. As participants join the web seminar and observe others exchanging support, they eventually come to see this behavior as the norm, which then further intensifies their attachment to the group (Blanchard, 2008). That is, as members engage in these kinds of supportive exchanges, they are building a sense of community. Previous scholarship explored support through asynchronous means but not the role of supportive chat comments in fostering a sense of community in web seminars. The unique contribution of our findings is that they suggest that same process occurs in the chat space of an online web seminar.

Regarding previous findings related to social practices, researchers have identified a number of key features that must exist to foster socialization in online communities. These features include learners' ability to identify with the community (Diaz, Swan, Ice, \& Kupczynski, 2010; Kreijns, Kirschner, Jochems \& Buuren, 2007) and their engagement in purposeful and open exchange of ideas and information (Diaz et al., 2010; Irwin \& Berge, 2006). Equally important are the existence of an atmosphere of trust that facilitates the construction of personal relationships (Garrison, Cleveland, Innes, \& Fung, 2010) and that the online space encourages self-expression (Diaz et al., 2010; Rourke, Anderson, Garrison, \& Archer, 1999). Based on our findings, we encourage scholars and practitioners to add exploration of productive disagreements among participants and formation of affinity groups to the current discussions of social practices within online web seminar spaces.

Lastly, the question remains regarding how the findings reported here connect to current theoretical understandings of the social dynamics of online web seminars. Figure 2 below illustrates how we believe the various components of Networked Spaces of Praxis fit together. Brown and Duguid (1991, 2001) developed the concept networks of practice to describe relations among group members, which are significantly looser than those in a community of practice. The 
participants in these networks may never actually meet each other in person, yet they are still able to share knowledge amongst themselves. They also characterize networks of practice as being less hierarchical than most CoPs in that members do not have to first earn status within the group before they can contribute knowledge. We have come to view oWL as a type of network rather than a community because involvement in the oWL space is quite fluid as participants come and go freely within and across seminars, yet interaction within the network nurtures a sense of belonging. The fluidity of the space may be encouraged by the fact that there is no formal membership required to participate in oWL seminars. Additionally, Gee (2009) contends that the feature of an affinity space that distinguishes it from a community of practice is that it is organized around the virtual space, while communities of practice are organized around membership (Lave, 1991). This lack of formal membership and the fluidity of the space also suggest that web seminar spaces like oWL may be better conceived as being organized around space rather than membership.

Praxis is the final component in our conception of the kind of online entity that oWL represents. Reich, Levinson, and Johnston (2011) discuss the use of online communities to develop praxis. They borrow from Freire's conception of the term, which they define as "the virtuous interplay of reflection and action in effective educational practice” (Reich, Levinson, \& Johnston, 2011, p. 382). We concur with their emphasis on the term praxis rather than practice "in order to emphasize the essential continued interplay of theory, reflection, and action" (Reich, Levinson, \& Johnston, 2011, p. 383). Anderson and Freebody (2012) also emphasize the praxis concept and add, "[The] community of praxis is ... seeking to reconcile the theoretical work done in university settings with the practice of everyday classrooms" (p. 362-363). Both of these definitions of a praxis-based community of learners correspond to our understanding of oWL. According to our findings related to knowledge sharing and socialization practices, oWL web seminars appear to organize around praxis to transform thinking about critical literacy, to move toward practice that is more ethical. That is, we posit that oWL web seminars organize around "mission” rather than membership or space.

As the preceding discussion illustrates, we have come to view oWL as an example of what we identify as an online networked space of praxis. That is, it consists of networks of participants who enter the web seminar space to engage in dialogue around how they can align their practice with current understandings of critical literacy. This space of praxis contrasts with typical communities of practice, or affinity spaces, which tend to focus more upon improving practice or solving practical problems. In this way, the oWL project self-consciously infuses an ethical dimension into the space that is missing in many other online learning groups.

Figure 2: Social Practices and Community Building in Online Networked Spaces of Praxis

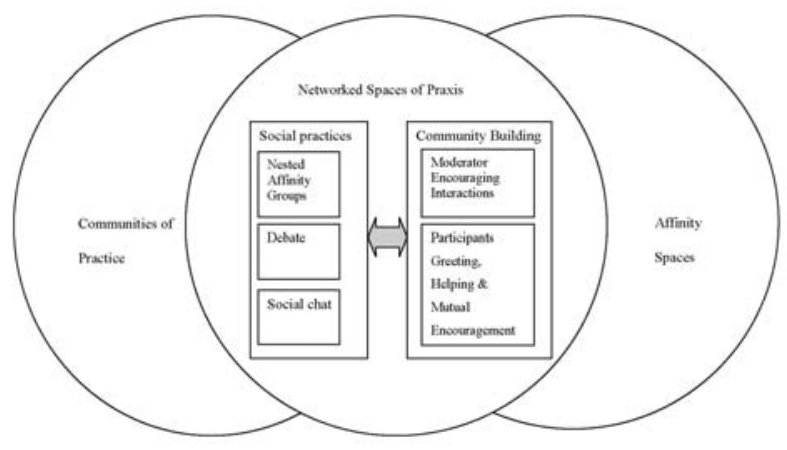




\section{Conclusion}

The present study addressed the following questions: (a) How are participants socialized into an online community interested in literacy, (b) how does "socialization" emerge in an on-going live literacy web seminar project, and (c) what social practices are visible within and across the web seminar project? We observed that oWL community building occurred through moderators and participants greeting, helping, and offering mutual encouragement. Additionally, social practices visible within and across seminars included social chat, respectful debate, and the formation of nested affinity groups.

Implications exist for both theory and practice related to online teacher professional development. In terms of expanding our understanding of online networked spaces of praxis, this study's findings inform us that participants' supportive actions contribute to the creation of a sense of community within an online venue such as oWLS. In addition, this research revealed that this online professional development web seminar provided a space where social practices like productive disagreement among participants can stimulate informative critical dialogue.

Findings from this study have the potential to influence the practice of online teacher professional development in two ways. First, they illuminate some of the potential actions that creators and stakeholders may need to undertake to build community in an online teacher professional development web seminar space. Secondly, these findings encourage web seminar developers to consider the benefits of harnessing social practices such as respectful debate of critical issues. As evidenced in the current study, such debates allow participants to engage with the ideas and their colleagues on a deeper level as they attempt to connect those ideas to their own pedagogical practice, with the ultimate goal of transformation.

Critical to transformation in education is the role of social presence in online professional development. While the platform itself isolates it also serves to bring an audience into socializing practices. The longer and more present a social space is, the more a participant will feel comfortable in these spaces to talk and to share ideas. In PD this is critical as often one-time PD does not offer this space. Especially in spaces like conferences where social presence is visible, what is less visible is the comfort with which participants will engage in social talk. Those whose research is around the topic under discussion and those who have confidence in their social roles will speak up while others will not. In online spaces, especially those that are on-going like oWL and focused on a topic in which those who attend have common interests in that topic, social presence is vital and can be cultivated. For example, [Ragina], who attends nearly all of the seminars, is socially present and has contact with others who also notice she is there.

Further, with mobile technologies, audiences can manage their social engagements and interactions to fit their lives and lifestyles, including their participation in web seminars. In increasing numbers, participants join web seminars not from computer-mediated communication (CMC) or Web 2.0 technologies, but from the convenience of their mobile devices. When [Participant 1] indicated her participation from a mobile device, such visibility opens up the possibility for those who view from their laptops or communities an idea that they can also join from anywhere and with alternative technological devices. What this suggests to us is that participants show interest, desire, and commitment to an area of research. Participants show keen interest in advancing their knowledge (professional development), a desire to share their 
thoughts with others and to engage in live discussions with the presenter and interested others, and a commitment to critical literacy as a space for transformation.

Mobile technologies and CMC provides alternative hardware from which to participate. That is, while [Participant 1] joined in on a mobile phone, others joined from iPads, laptops, and desktops. For us, this suggests that social presence is extremely important to supporting online $\mathrm{PD}$, and flexibility in the use of technologies offers opportunities for all to engage in live conversations. The use of mobile and CMC devices increases proximity as well as immediacy of personal communication. In this way oWL creates a space where participants can be close together while also being far apart. With increased mobile device use and oWL participation, we argue that mobile devices have decreased the social presence space and increased the space for socializing and socialization. Mobile devices manage social acts at anytime and anywhere through mobile technologies

We acknowledge potential limitations of this study that include some uncertainties regarding the straightforward generalizability of our findings to other contexts, and the threat of bias in our analysis given our participation in the project. The community building dynamics and productive disagreement and debate observed in oWL offer tantalizing examples of the unique possibilities these web seminars may offer to enhance literacy teacher professional development. However, we must also consider that these observations made within the oWL may not look quite the same in other online spaces and communities. Secondly, we acknowledge that, unbeknownst to us, our role as oWL moderators might have had some inadvertent impact on our perceptions of the data. Nevertheless, these limitations mainly point to prospective avenues for future research. That is, other investigators might explore in other online spaces the dynamics around community building and debate that we observed to determine the strength our findings.

\section{References}

Albers, P., Pace, C., \& Brown, D.W., Jr. (2013). Critical participation in literacy research through new and emerging technologies: A study of web seminars and global engagement. Journal of Literacy and Technology, 14(2), 78-114.

Ally, M., \& Samaka, M. (2013). Open education resources and mobile technology to narrow the learning divide. The International Review of Research in Open and Distributed Learning, 14(2), 14-27.

Amin, A., \& Roberts, J. (2008). Knowing in action: Beyond communities of practice. Research Policy, 37(2), 353-369.

Anderson, M. J., \& Freebody, K. (2012). Developing communities of praxis: Bridging the theory practice divide in teacher education. McGill Journal of Education, 47(3), 359-377.

Andrade A., Caine A., Carneiro R., Conole G., Ehlers U.-D., Holmberg C., Kairamo A.-K., Koskinen T., Kretschmer T., Moe-Pryce N., Mundin P., Nozes J., Reinhardt R., Richter T., \& Silva G. (2011). Beyond OER - Shifting focus to open educational practices. OPAL Report 2011. Retrieved from http://nbnresolving.de/urn/resolver.pl?urn=urn:nbn:de:hbz:464-20110208-115314-6 
Ashby, J., Sadera, W. A., \& McNary, S. W. (2011). Comparing student success between developmental math courses offered online, blended, and face-to-face. Journal of Interactive Online Learning, 10(3), 128-140.

Blanchard, A. L. (2008). Testing a model of sense of virtual community. Computers in Human Behavior, 24(5), 2107-2123.

Bogdan, R. C., \& Biklen, K. S. (2007). Qualitative research for education: An introduction to theories and methods (5th ed.). New Delhi, India: Pearson.

Booth, S. E. (2012). Cultivating knowledge sharing and trust in online communities for educators. Journal of Educational Computing Research, 47(1), 1-31.

Bransford, J., Brophy, S., \& Williams, S. (2000). When computer technologies meet the learning sciences: Issues and opportunities. Journal of Applied Developmental Psychology, 21(1), 59-84.

Brooks, C. (2010). Toward "hybridised" faculty development for the twenty-first century: Blending online communities of practice and face-to-face meetings in instructional and professional support programmes. Innovations in Education and Teaching International, 47, 261-270.

Brown, J. S., Collins, A., \& Duguid, P. (1989). Situated cognition and the culture of learning. Educational Researcher, 18(1), 32-42.

Brown, J. S., \& Duguid, P. (1991). Organizational learning and communities of practice: Towards a unified view of working, learning, and innovation. Organization Science, 2, 40-57.

Brown, J. S., \& Duguid, P. (2001) 'Knowledge and organization: A social-practice perspective. Organization Science, 12(2), 198-215.

Butler, B., Sproull, L., Kiesler, S., \& Kraut, R. (2007). Community effort in online groups: Who does the work and why? Human-Computer Interaction Institute. Paper 90. http://repository.cmu.edu/hcii/90

Caelli, K., Ray, L., \& Mill, J. (2003). 'Clear as mud’: Toward greater clarity in generic qualitative research. International Journal of Qualitative Methods, 2(2), 1-13.

Carr, N., \& Chambers, D. P. (2006). Teacher professional learning in an online community: The experiences of the National Quality Schooling Framework Pilot Project. Technology, Pedagogy and Education, 15(2), 143-157.

Chen, Y., Chen, N., \& Tsai, C. (2009). The use of online synchronous discussion for web-based professional development for teachers. Computers \& Education, 53, 1155-1166.

Chiu, C. M., Hsu, M. H., \& Wang, E. T. (2006). Understanding knowledge sharing in virtual communities: An integration of social capital and social cognitive theories. Decision Support Systems, 42(3), 1872-1888.

Clarke, M. (2009). The discursive construction of interpersonal relations in an online community of practice. Journal of Pragmatics, 41(11), 2333-2344. 
Corbin, J. M., \& Strauss, A. (1990). Grounded theory research: Procedures, canons, and evaluative criteria. Qualitative Sociology, 13(1), 3-21.

Courtney, A. M., \& King, F. B. (2009). Online dialog: A tool to support preservice teacher candidates' understanding of literacy teaching and practice. Contemporary Issues in Technology and Teacher Education, 9(3), 226-256.

Diaz, S., Swan, K., Ice, P., \& Kupczynski, L., (2010). Student ratings of the importance of survey items, multiplicative factor analysis, and the validity of the community of inquiry survey. Internet and Higher Education, 13, 22-30.

Ehlers, U. D. (2011). Extending the territory: From open educational resources to open educational practices. Journal of Open Flexible and Distance Learning, 15(2), 1-10.

Floding, M., \& Sweir, G. (2012). Legitimate peripheral participation: Entering a community of practice. Reflective Practice, 31, 193-204.

Garrison, D.R., Cleveland, Innes, M., \& Fung, T., (2010). Exploring causal relationships among teaching, cognitive and social presence: Student perceptions of the community of inquiry framework. Internet and Higher Education, 13, 31-36.

Gee, J. P. (2009). Affinity spaces: From Age of Mythology to today’s schools. Retrieved from http://jamespaulgee.com/node

Gee, J. P. (2010). New digital media and learning as an emerging area and "worked examples” as one way forward. Retrieved from http://ehis.ebscohost.com/eds/ebookviewer/ ebook/nlebk_307695_AN?sid=1c537d2d-518b-4353-8d72-c3f377d32822 @sessionmgr $113 \&$ vid=1\&hid=116\&format $=$ EB

Gibbs, G. R. (2008). Analyzing qualitative data. Los Angeles: Sage.

Glaser, B. G., \& Strauss, A. (1967). The discovery of ground theory. New York, NY: Alpine.

Glesne, C. (1998). Becoming qualitative researchers: An introduction. White Plains, NY: Longman.

Gray, B. (2004). Informal learning in an online community of practice. Journal of Distance Education, 19(1), 20-35.

Gurell, S., Kuo, Y. C., \& Walker, A. (2010). The pedagogical enhancement of open education: An examination of problem-based learning. The International Review of Research in Open and Distributed Learning, 11(3), 95-105.

Hatch, J. A. (2002). Doing qualitative research in education settings. Albany: SUNY Press.

Hylén, J. (2006). Open educational resources: Opportunities and challenges. Proceedings of Open Education, Utah State University, Logan, Utah, 27-29 September. Available at: https://www.researchgate.net/profile/Jan_Hylen/publication/235984502_Open_education al_resources_Opportunities_and_challenges/links/54d321a80cf250179181779b.pdf. 
Irwin, C., \& Berge, Z. (2006). Socialization in the online classroom. E-Journal of Instructional Science and Technology, 9(1), 1-7. Retrieved from http://www.ascilite.org.au/ajet/ejist/docs/vol9_no1/papers/full_papers/irwin_berge.pdf.

Keller, P., \& Mossink, W. (2008). Reuse of material in the context of education and research. SURFfoundation. Retrieved from http://www.surffoundation.nl/SiteCollectionDocuments/Report_SURFCC_Reuse\%20of \%20material_Eng_DEF.doc

Kop, R., Fournier, H., \& Mak, J. S. F. (2011). A pedagogy of abundance or a pedagogy to support human beings? Participant support on massive open online courses. The International Review of Research in Open and Distributed Learning, 12(7), 74-93.

Kreijns, K., Kirschner, P., Jochems, W., \& Buuren, H. (2007). Measuring perceived sociability of computer-supported collaborative learning environments. Computers and Education, 49, 176-192.

Lave, J. (1991). Situating learning in communities of practice. In L. B. Resnick, J. M. Levine, \& S. D. Teasley (Eds.), Perspectives on socially shared cognition (pp. 63-82). Retrieved from http://www.udel.edu/educ/whitson/files/Lave,\%20Situating\%20learning\%20in\%20comm unities\%20of\%20practice.pdf

Lave, J., \& Wenger, E. (1991). Situated learning: Legitimate peripheral participation. New York, NY: Cambridge University Press.

Li, L., Grimshaw, J., Nielsen, C., Judd, M., Coyte, P., \& Graham, I. (2009) Evolution of Wenger's concept of community of practice. Implementation Science, 4(1), 11.

Lichtman, M. (2012). Qualitative research in education: A user's guide. Los Angeles: Sage.

Merriam, S. B. (2009). Qualitative research: A guide to design and implementation. San Francisco: Jossey-Bass.

Olcott, D. (2012). OER perspectives: Emerging issues for universities. Distance Education, 33(2), 283-290.

Reich, J., Levinson, M., \& Johnston, W. (2011). Using online social networks to foster preservice teachers' membership in a networked community of praxis. Contemporary Issues in Technology and Teacher Education, 11(4), 382-397.

Rourke, L., Anderson, T., Garrison, D. R., \& Archer, W. (1999). Assessing social presence in asynchronous text-based computer conferencing. Journal of Distance Education, 14(2), 50-71.

Santally, M. (2005). From face-to-face classrooms to innovative computer-mediated pedagogies: Observations from the field. Journal of Interactive Online Learning, 3(4), 1-14.

Schallert, D. L., Chiang, Y. H. V., Park, Y., Jordan, M. E., Lee, H., Cheng, A. C. J., Chu, H. N. R., Lee, S. A., Kim, T., \& Song, K. (2009). Being polite while fulfilling different 
discourse functions in online classroom discussions. Computers \& Education, 53(3), 713725.

Sing, C. C., \& Khine, M. S. (2006). An analysis of interaction and participation in online community. Educational Technology \& Society, 9(1), 250-261.

Takahashi, S. (2011). Co-constructing efficacy: A “communities of practice” perspective on teachers’ efficacy beliefs. Teaching and Teacher Education, 27(4), 732-741.

Vonderwell, S. (2003). An examination of asynchronous communication experiences and perspectives of students in an online course: A case study. The Internet and Higher Education, 6(1), 77-90.

Wanstreet, C. E., \& Stein, D. S. (2011). Presence over time in synchronous communities of inquiry. American Journal of Distance Education, 25(3), 162-177.

Wellman, B., \& Guilia, M. (1999). Net surfers don’t ride alone: Virtual communities as communities. In B. Wellman (Ed.), Networks in the global village: Life in contemporary communities (pp. 331-366). Boulder, CO: Westview.

Wenger, E. (1996). Communities of practice: The social fabric of a learning organization. Healthcare Forum, 39(4), 20-26.

Wenger, E. (1998). Communities of practice: Learning, meaning, and identity. Cambridge, U.K.: Cambridge University Press.

Wenger, E. (2000). Communities of practice and social learning systems. Organization, 7(2), 225-246. doi: 10.1177/135050840072002.

Wenger, E. (2009). Communities of practice and social learning systems: The career of a concept. In C. Blackmore (Ed.), Social learning systems and communities of practice (pp. 179-198). New York, NY: Springer London.

Wenger, E., McDermott, R., \& Snyder, W. M. (2002). Cultivating communities of practice: A guide to managing knowledge. Boston, MA: Harvard Business School Press.

Wilson, T., \& Whitlock, D. (1998). Monitoring the online behavior of distance learning students. Journal of Computer Assisted Learning, 14, 91-99. 